\title{
International Particle Physics Outreach Group: Reaching across the globe with science
}

\author{
Pedro Abreu ${ }^{a, *}$ (for the IPPOG Collaboration) \\ $a_{L I P}$ and IST, \\ Av.Prof. Gama Pinto, 2, 1649-003 Lisboa, Portugal \\ E-mail: abreu@ip.pt
}

The International Particle Physics Outreach Group (IPPOG) is a network of scientists, science educators and communication specialists working across the globe in informal science education and outreach for particle physics. The primary methodology adopted by IPPOG requires the direct involvement of scientists active in current research with education and communication specialists, in order to effectively develop and share best practices in outreach. IPPOG member activities include the International Particle Physics Masterclass programme, International Day of Women and Girls in Science, Worldwide Data Day, International Muon Week and International Cosmic Day organisation, and participation in activities ranging from public talks, festivals, exhibitions, teacher training, student competitions, and open days at local institutions. These independent activities, often carried out in a variety of languages to public with a variety of backgrounds, all serve to gain the public trust and to improve worldwide understanding and support of science. We present our vision of IPPOG as a strategic pillar of particle physics, fundamental research and evidence-based decision-making around the world.

The Ninth Annual Conference on Large Hadron Collider Physics - LHCP2021

7-12 June 2021

Online

*Speaker 


\section{Introduction}

Particle Physics today faces several major challenges, from physics problems to technologies, from present experiments to future accelerators, from public engagement to the preparation of the future generations of scientists.

IPPOG - International Particle Physics Outreach Group [1] is a global network of researchers with experience in Education and Outreach and experts in Communication and Education, committed to address the challenges associated to Education and Outreach of Particle and Astroparticle Physics and associated technologies, to engagement of Society in this quest, to increase globally the scientific literacy and prepare the next generation of scientists and engineers in our field.

IPPOG is an international collaboration with 37 members comprising 30 countries, 6 international experiments and 1 international laboratory (CERN), and 2 national laboratories as associate members (DESY, GSI).

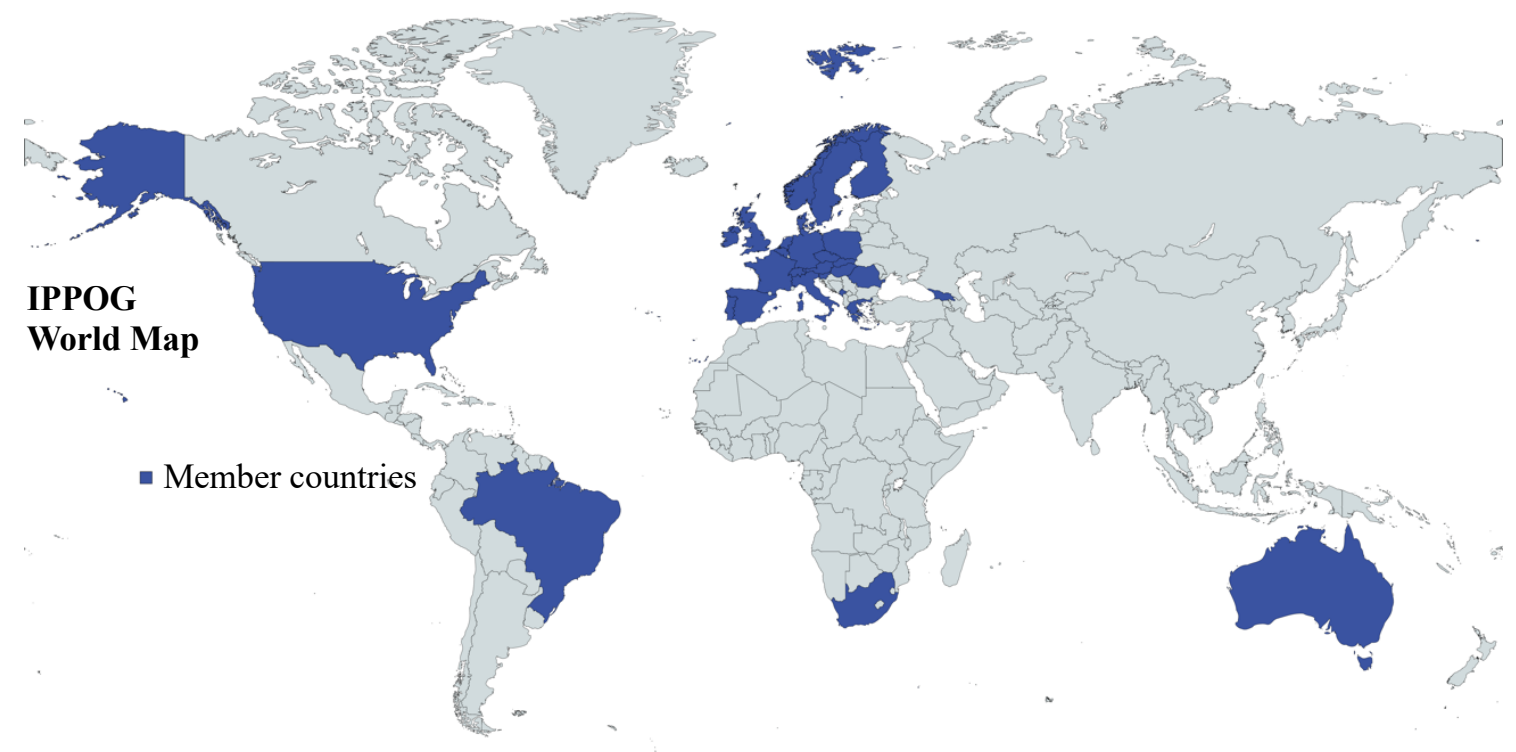

IPPOG organizes global activities, such as the International Particle Physics Masterclasses (IMC) and the World Wide Data Day (W2D2), promotes the International Cosmic Day (ICD) and the International Muon Week (IMW), maintains the Global Cosmics network of projects associated to cosmic rays, and supports local activities, such as science festivals, kick-start activities, public sessions at major conferences and meetings, etc.

IPPOG maintains a database of resources useful to our colleagues and to teachers and students interested in particle physics, with contents provided and validated by the particle physics community.

IPPOG meets twice a year for its members, associate members, and invited people to share best practices, useful expertise, tools, information from local events, etc.

\section{Goals}

The goals of IPPOG include the sustainable development of education and outreach in Particle and Astroparticle Physics, working towards this goal in discussion forums for scientists 
and communicators active in outreach and informal education, sharing information and best practices between individuals, institutions, and laboratories, in meetings and active working groups addressing specific challenges of global outreach. Another goal is about improving outreach standards worldwide, developing strategies, practices and explanatory materials based on experience, interactions with our target audiences and public, and discussing the methodologies and results between peers. Finally, another important goal is to significantly extend our global reach, namely expansion to countries and peoples underrepresented in particle physics, usage of methods, topics, and activities, to reach broader audiences, and active online communication platforms.

\section{Activities}

Besides its two annual meetings in which participants share experiences and report on successful activities, working and steering groups present the evolution of its developments, and a focussed panel discusses a relevant or urgent topic in need of our attention, IPPOG develops global activities such as the International Masterclasses and Global Cosmics.

The International Masterclasses - hands-on Particle Physics (IMC) is the flagship activity of IPPOG for high-school students (ages 15-18 years). In this one-day activity, students are invited to a university or research institute, to "Be a Scientist for a Day - with the hands-on particles". Typically, the participants start with introductory lectures and laboratory visits in the morning, analyse real data immediately after a quick lunch, and participate in an international videoconference moderated by physicists based at one of the partner hubs (CERN, Fermilab, GSI, KEK, TRIUMF). The real data and software are provided by the Experiments ATLAS, CMS, ALICE, LHC-b, Belle-II and MINERvA. In the "Proton Therapy" masterclass, participants use simulation software to prepare the best treatment plans using particle beams.

The IMC was launched in 2005, following the similar Masterclasses run at UK Universities, but adding in IMC the video linkup at the end of the day, for the participants to discuss their results among themselves and with other participants from institutes around the world organizing an IMC in the same day, moderated by scientists a partner hub. In its first edition participated 3000 students from 18 countries in 58 institutes, and the activity was very successful among highschool students [2,3], reaching in 2019 - the last year with normal organization before pandemic crisis - about 14000 students from 60 countries in 220 institutions [4].

The Global Cosmics is the other flagship activity of IPPOG, featuring a network of cosmic rays projects for schools and for interested public, using detectors and/or real data from experiments in astroparticle physics. Global Cosmics is behind the organization of the International Cosmic Day(s) (https://icd.desy.de) for teachers and students to share the results obtained in their experiments and in their analyses, and supports Quarknet in the organization of International Muon Week(s) (https://quarknet.org/content/international-muon-week). Global Cosmics encourages the sharing of the data, the methods, the tools, and the know-how in the preparation of detectors for use in school environments and with diverse publics.

Many other projects and activities are organized and carried out by IPPOG Collaborators, namely public sessions in large conferences and science festivals, science pavilions at large events including music festivals, outreach talks in schools and large auditoriums, open days at 
laboratories and universities, research institutions and facilities, or going to meet the public in special events, such as science weeks and researchers' nights (of which the "European Researchers Nights" have an important role). Either in presence or online, our scientists are eager to engage with the public in general and students in particular.

\section{Challenges}

Although IPPOG is already carrying a lot of activities, bringing the science and the scientists to the public and to the schools, there are some challenges to be faced that continuously defy our ingenuity and mobilisation capacity. Among the most important we recognize the following:

- Scale of [new] experiments/facilities/projects - be it due to the timespan in the order of decades now, the huge cost, the very large size, the technology needs.

- Wide[r] recognition of the value of Science in Society - namely to increase its scientific literacy and the amount of people that take informed and evidence-based decisions on matters important to us all. This fights the spread of disinformation, especially in the high-speed information exchange internet social networks.

- Increase the reach of our activities - geographically, as there are still many regions and countries in the world that are not scientifically aware and do not participate in this global endeavour; in diversity and inclusion, as even in our member countries with populations not scientifically aware and that feel excluded from science; and in age, as we need to reach younger audiences and talk about science to kids of very early ages (for example, starting already in kindergarten and primary schools).

- Train the trainers - the teachers at the schools are our vehicles of communication and dissemination of science to the future generations, that need constant training and updating of their knowledge; but we need to train also the Scientists to do good outreach and communication, and all colleagues that want to engage with public and students to make the most out of the experience.

- Finally, we must start/help the process of including concepts from basic particle physics and high energy physics in the curriculum of schools. Naturally this challenge is coupled to the previous one, because only knowledgeable and wellprepared teachers can launch the discussion of these concepts with their students.

\section{Conclusions}

Education, Communication and Outreach are essential pillars for the development of High Energy and Particle Physics. Many scientists, at different levels of commitment, along with experts in outreach and communication, are already carrying outwards the excitement of the field with many activities.

Our field needs the support and contribution of all of you [including the readers!],

- as actively being an ambassador of the field,

- as speaker/moderator/motivator/organiser/educator/supervisor,

- as evaluator of projects/careers assessments/applications/positions,

- and/or helping creating the conditions for a better Edu.-Comm.-OR in HEP\&PP.

\section{O_TREACH is not complete without $\mathrm{U}$}




\section{References}

[1] http://www.ippog.org

[2] "Masterclass spreads the word for physics", M. Kobel, CERN Courier, 28 Sep 2005: https://cerncourier.com/a/masterclass-spreads-the-word-for-physics.

[3] "International Masterclasses in the LHC era", M. Bardeen et al., CERN Courier, 22 May 2014: https://cerncourier.com/a/international-masterclasses-in-the-lhc-era/.

[4] “Current Status of International Masterclasses", U. Bilow and K. Cecire, ICHEP2020, July 2020: https://indico.cern.ch/event/868940/contributions/3814087/attachments/2080598/3498844/2020_07 _ichep_current_status_of_imc_v4.pdf. 